\title{
H. M.'s Medial Temporal Lobe Lesion: Findings from Magnetic Resonance Imaging
}

\author{
Suzanne Corkin,, ${ }^{1}$ David G. Amaral, ${ }^{2}$ R. Gilberto González, ${ }^{3}$, Keith A. Johnson, ${ }^{4}$ and Bradley T. Hyman ${ }^{5}$ \\ ${ }^{1}$ Department of Brain and Cognitive Sciences and the Clinical Research Center, Massachusetts Institute of Technology, \\ Cambridge, Massachusetts 02139, 2Department of Psychiatry and Center for Neuroscience, University of California, \\ Davis, Davis, California 95616, ${ }^{3}$ Nuclear Magnetic Resonance Center and Neuroradiology Section, Massachusetts \\ General Hospital, Harvard Medical School, Boston, Massachusetts 02114, ${ }^{4}$ Departments of Neurology and Radiology, \\ Brigham and Women's Hospital, Harvard Medical School, Boston, Massachusetts 02115, and 5epartment of \\ Neurology, Massachusetts General Hospital, Harvard Medical School, Boston, Massachusetts 02114
}

\begin{abstract}
Although neuropsychological studies of the amnesic patient $H$. M. provide compelling evidence that normal memory function depends on the medial temporal lobe, the full extent of his surgical resection has not been elucidated. We conducted magnetic resonance imaging studies to specify precisely the extent of his bilateral resection and to document any other brain abnormalities. The MRI studies indicated that the lesion was bilaterally symmetrical and included the medial temporal polar cortex, most of the amygdaloid complex, most or all of the entorhinal cortex, and approximately half of the rostrocaudal extent of the intraventricular portion of the hippocampal formation (dentate gyrus, hippocampus, and subicular complex). The collateral sulcus was visible throughout much of the temporal lobe, indicating that portions of the ventral perirhinal cortex, located on the banks of the sulcus, were spared; the parahippocampal cortex (areas TF and $\mathrm{TH}$ ) was largely intact. The
\end{abstract}

rostrocaudal extent of the ablation was $\sim 5.4 \mathrm{~cm}$ (left) and 5.1 $\mathrm{cm}$ (right). The caudal $2 \mathrm{~cm}$, approximately, of the hippocampus body (normal length, $\sim 4 \mathrm{~cm}$ ) was intact, although atrophic. The temporal stem was intact. Outside the temporal lobes, the cerebellum demonstrated marked atrophy, and the mammillary nuclei were shrunken. The lateral temporal, frontal, parietal, and occipital lobe cortices appeared normal for age 66 years. The mediodorsal thalamic nuclei showed no obvious radiological changes. These findings reinforce the view that lesions of the hippocampal formation and adjacent cortical structures can produce global and enduring amnesia and can exacerbate amnesia beyond that seen after more selective hippocampal lesions.

Key words: amnesia; medial temporal lobe; human; explicit/ declarative memory; MRl; epilepsy surgery; H. M.
At the 1953 meeting of the Harvey Cushing Society, Scoville (1954) discussed two patients (one epileptic, H. M., and the other schizophrenic) in whom he had performed "bilateral resection of the entire (pyriform-amygdaloid-hippocampal) complex including the hippocampal gyrus extending posteriorly for a length of $8-9 \mathrm{~cm}$ from the tips of the temporal lobes." He reported that both patients experienced "a very grave, recent memory loss" ( $p$ 65). Independent of Scoville's report, Milner and Penfield (1955) documented a similar impairment in two patients after left temporal lobectomy. At autopsy, one of them had a substantial lesion in the right hippocampal formation (Penfield and Mathieson, 1974); the other was presumed (based on electroencephalography

\footnotetext{
Received Jan. 28, 1997; accepted Feb. 7, 1997.

This work was supported by National Institutes of Health (NIH) Grants AG 06605 and AGNS 08117 (S.C.) and NS 16980 and MH R3741479 (D.G.A.), and by the Human Frontier Science Program (D.G.A.). The MIT Clinical Research Center (CRC) is supported by NIH Grant RR00088. We are grateful to Brenda Milner for permission to study H. M., Peter Black for helping us initiate this project, Richard B Schwartz for performing the MRI scan at the Brigham and Women's Hospital, and Rosamund Hill and Steven W. Parker of the Massachusetts General Hospital for performing the EEG. We also thank Pierre Gloor, Leyla deToledo-Morrell, Frank Morrell, Elisabeth A. Murray, and Larry Squire for valuable discussions. We acknowledge with thanks the special care given to H. M. by the CRC staff. We also thank Kris Trulock for photographic assistance.

Correspondence should be addressed to Dr. Suzanne Corkin, E10-003A, MIT, Cambridge, MA 02139.

This paper is dedicated with appreciation to H. M., whose loss of memory has provided us with a wealth of information concerning the organization of memory. Copyright (C) 1997 Society for Neuroscience $0270-6474 / 97 / 173964-16 \$ 05.00 / 0$
}

and the presence of automatism) (Feindel and Penfield, 1954; Penfield and Milner, 1958) to have a preoperatively unsuspected lesion in the right medial temporal lobe. Scoville realized his patients' importance for the understanding of human memory mechanisms, and when he learned of Penfield and Milner's findings, he invited them to examine his patients. The resulting paper (Scoville and Milner, 1957) described the findings for nine schizophrenic patients and H. M. Based on analyses of patients with three different types of medial temporal lobe ablations compromising various rostrocaudal amounts of the intraventricular portion of the hippocampal formation, the authors concluded that the severity of the memory impairment was related to the extent of resection of the hippocampus and parahippocampal gyrus bilaterally. The severe and lasting anterograde amnesia was in sharp contrast to their preserved early memories and overall intelligence.

The significance of this paper (Scoville and Milner, 1957) was fourfold: (1) it informed neurosurgeons that a bilateral lesion of medial temporal lobe structures placed recent memory functions at risk; (2) it suggested that the establishment of memory had a distinct neural substrate; memory for new experiences was disturbed, but other cognitive functions and sensory capacities were unimpaired; (3) it inaugurated 4 decades of experimental studies of H. M. (Milner et al., 1968; Corkin, 1984); and (4) it inspired animal models of human amnesia (Correll and Scoville, 1965). The animal models, together with the human studies, demonstrate 


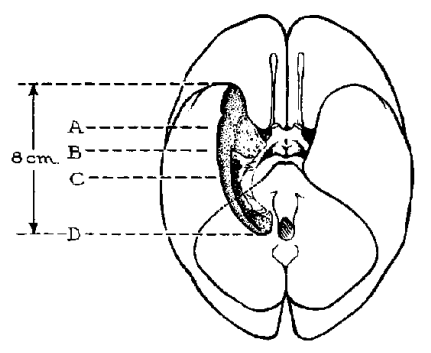

A

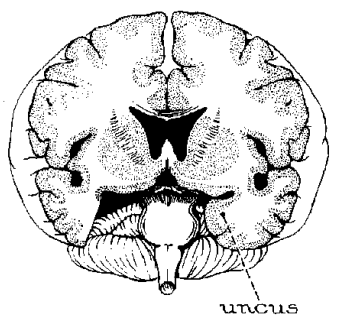

C

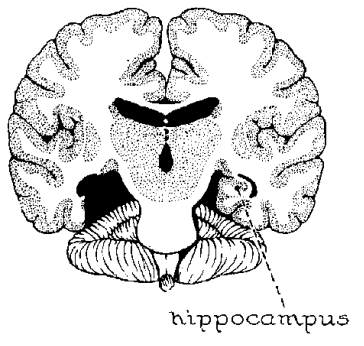

B

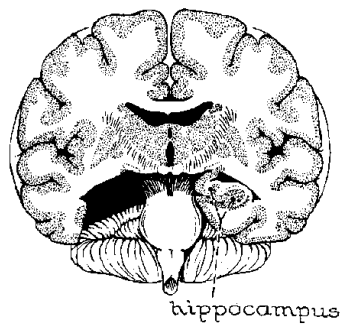

D

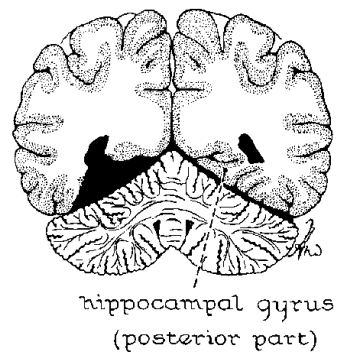

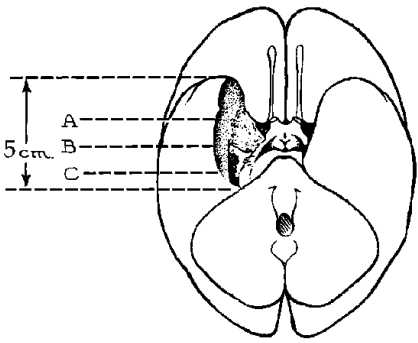

A

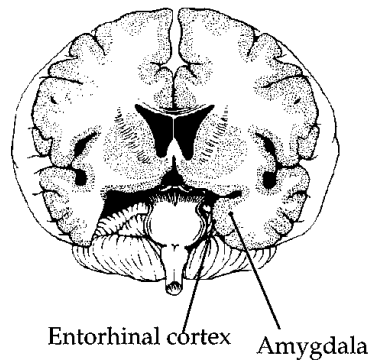

B

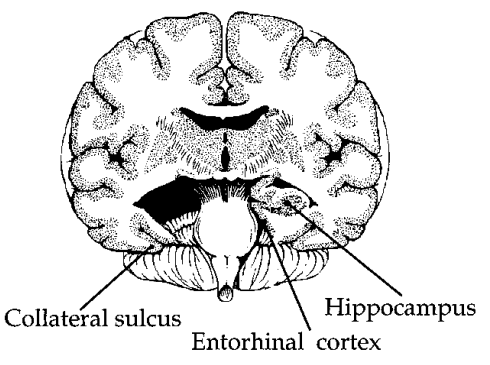

$\mathrm{D}$
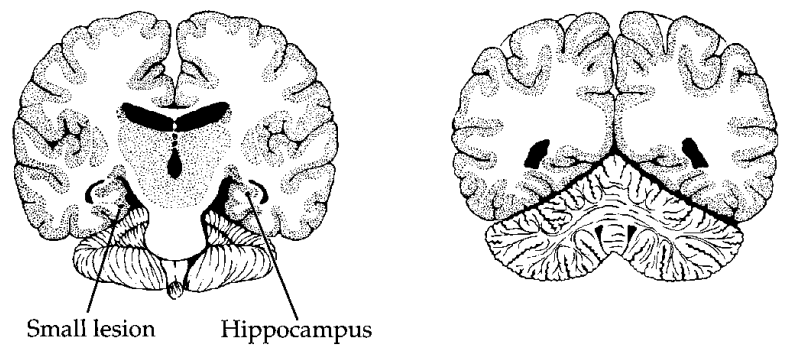

Figure 1. Left, Diagram showing the surgeon's estimate of H. M.'s medial temporal lobe resection (Scoville and Milner, 1957, their Fig. 2, p 13). The inset at the top is a ventral view of the human brain showing the predicted rostrocaudal extent of the ablation. $A$ through $D$ are drawings of coronal sections, arranged from rostral $(A)$ to caudal $(D)$, showing the predicted extent of the lesion. Note that although the lesion was made bilaterally, the right side is shown intact to illustrate structures that were removed. Right, An amended version of the original diagram indicating the extent of the ablation based on the MRI studies reported here. The rostrocaudal extent of the lesion is $5 \mathrm{~cm}$ rather than $8 \mathrm{~cm}$, and the lesion does not extend as far laterally as initially pictured.

that medial temporal lobe structures are critical for establishing long-term explicit/declarative memory (Squire, 1992).

Because previous imaging studies of H. M. did not reveal the precise extent of his temporal lobe lesion (Corkin, 1984), hypotheses concerning the neuroanatomical substrate of his amnesia have been based on Scoville's surgical report. This uncertainty has prompted speculation (Horel, 1978) that lesions in structures other than the hippocampal formation may explain the memory impairment. Moreover, recent studies in animal models of human amnesia have raised questions about which temporal lobe structures included within the ablation in H. M. contribute to normal memory function (Mishkin and Murray, 1994). For example, the perirhinal cortex has been shown to be an important component of the medial temporal lobe memory system in the monkey (Zola-Morgan et al., 1989c, 1993; Meunier et al., 1993; Suzuki et al., 1993), but it is currently unclear to what extent this region is damaged in $\mathrm{H}$. M. The present study used magnetic resonance imaging (MRI) to survey the structure of H. M.'s entire brain to specify the damage to particular medial temporal lobe structures and to document any other brain lesions.

\section{MATERIALS AND METHODS}

Case history of the patient H. M. At the time of the imaging studies (May, 1992 and August, 1993), H. M. was 66 and 67 years old, respectively. He was born in Manchester, CT, in 1926. At age 9 years, he was knocked down by a bicycle. He sustained a laceration of the left supraorbital region and was unconscious for $\sim 5 \mathrm{~min}$. He experienced his first minor seizure (atypical petit mal) at age 10 years and his first generalized convulsion at age 16 . We assume that the seizures are a consequence of his head injury, but there also is a paternal history of epilepsy. H. M. graduated from high school at age 21, having dropped out of school for several years for reasons related to his epilepsy. After high school, he obtained a position as a motor winder but had to relinquish that job because of the frequency and severity of his seizures. When high doses of the available anticonvulsant medications did not provide adequate seizure control, H. M.'s family consulted Dr. William Beecher Scoville at the Hartford Hospital about a brain operation to relieve his epilepsy.

Scoville offered $\mathrm{H}$. M. a procedure that had been performed previously only in psychotic patients (Scoville et al, 1953). In 1953, when H. M. was

Figure 2. T1-weighted series of coronal sections arranged from caudal $(A)$ to rostral $(P)$ to show the extent of the lesion in H. M. (see text for details). Scale bars (shown in $L$ and $P$ ), $2 \mathrm{~cm}$. Figure continues. 

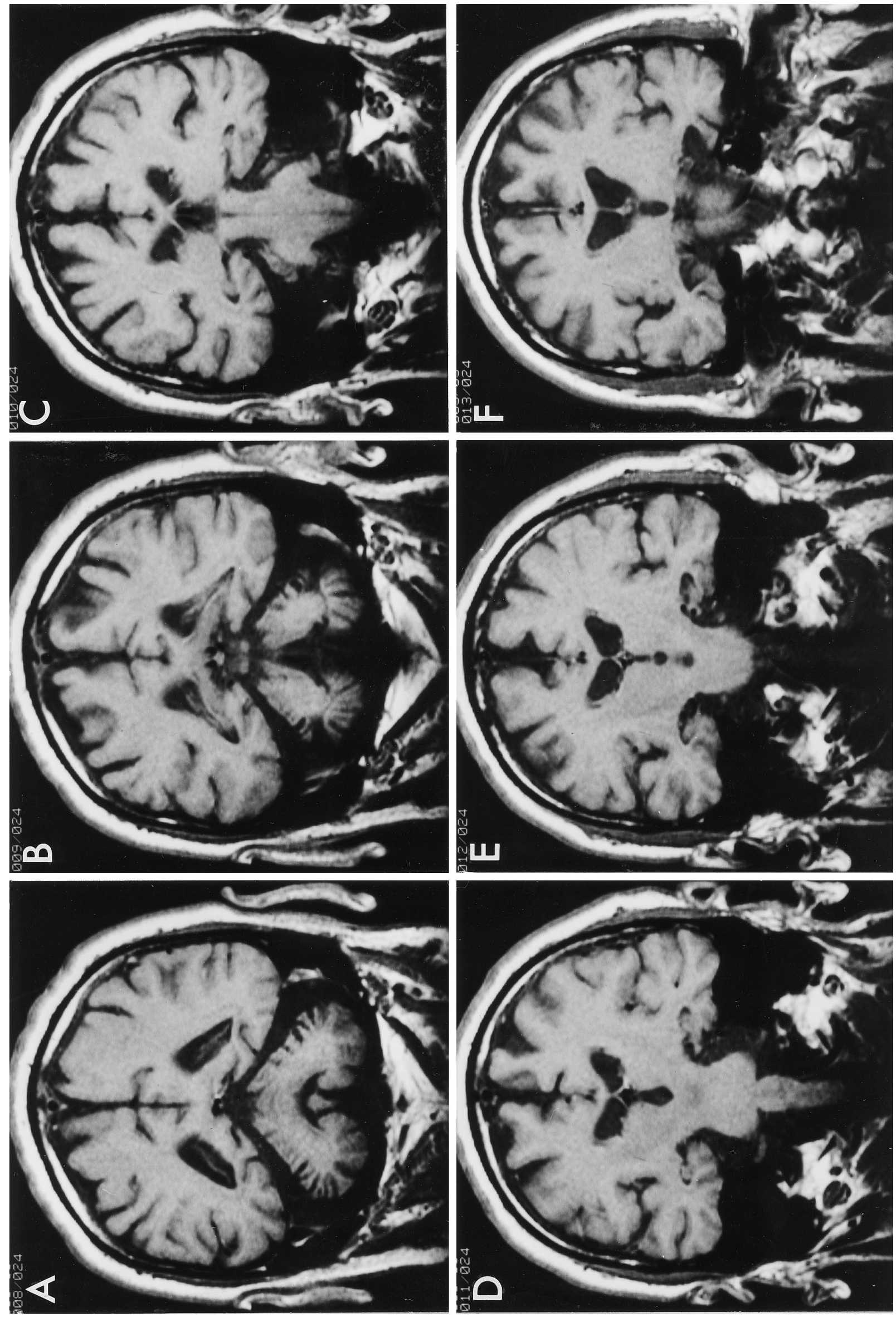

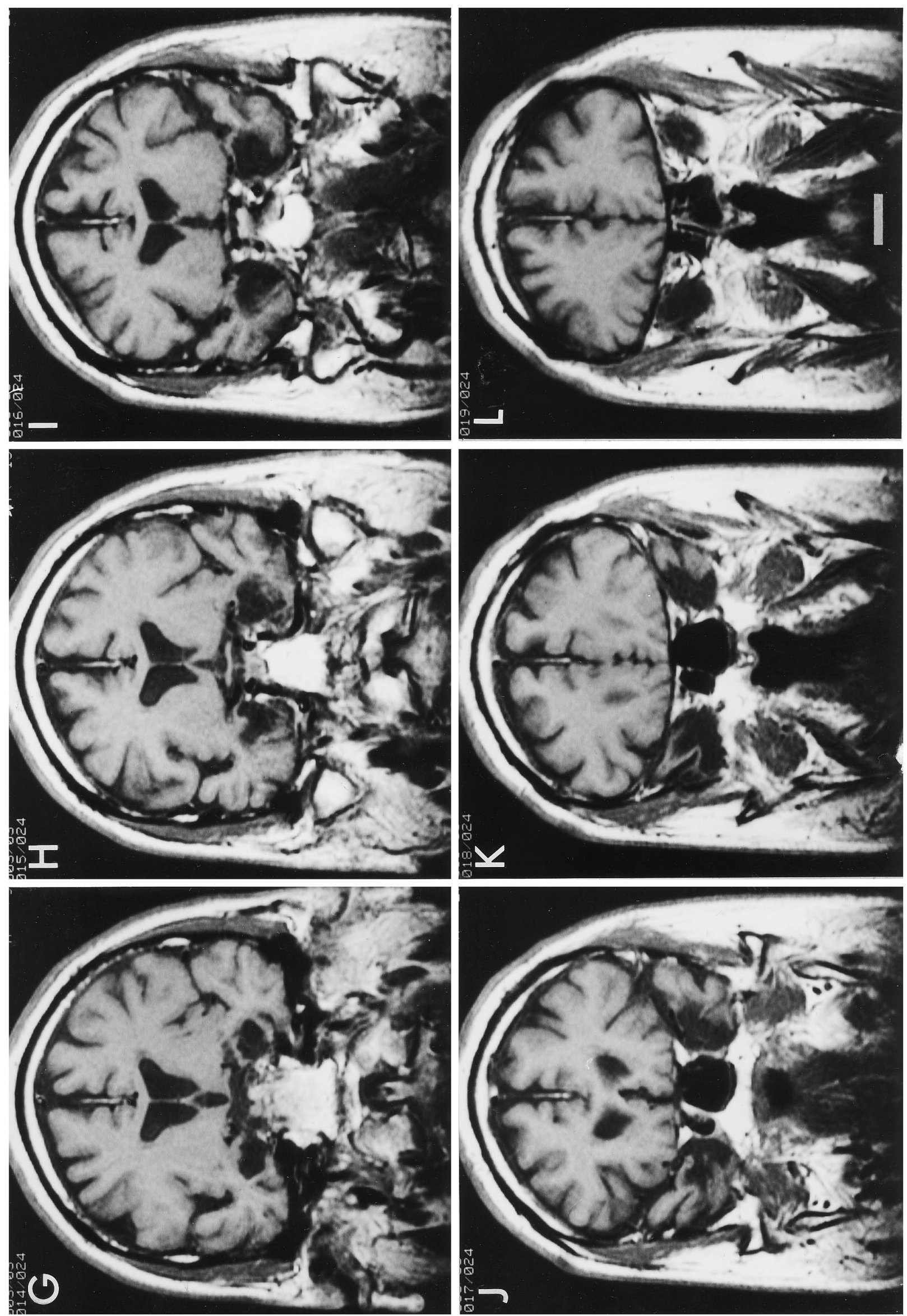

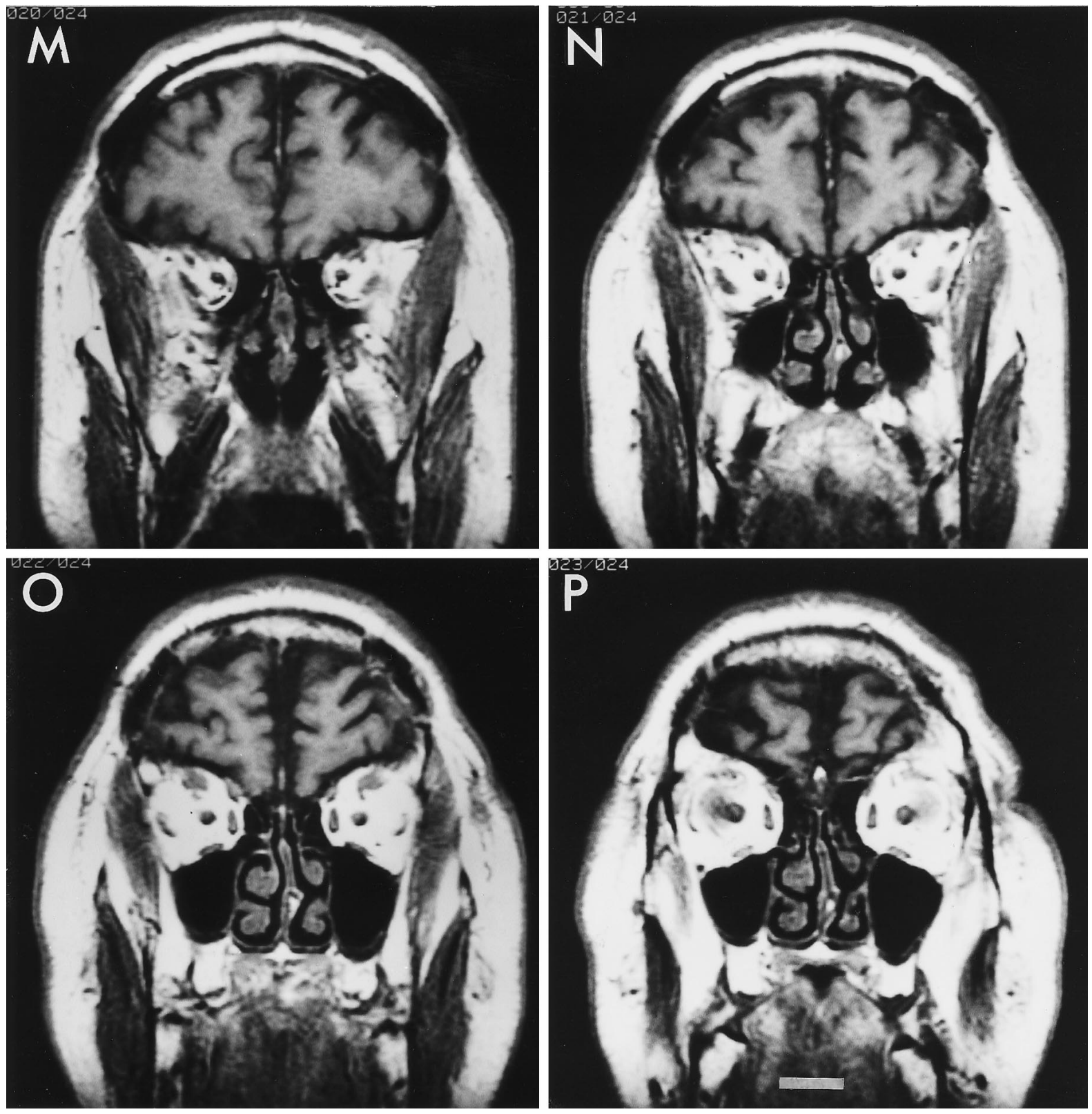

Figure 2 continued.

27 years old, he underwent "this frankly experimental operation" (Scoville and Milner, 1957, p 11): a bilateral medial temporal lobe resection. At the time of operation, Scoville estimated that the removal included $8 \mathrm{~cm}$ of medial temporal lobe tissue, including the temporal pole, amygdaloid complex, and approximately two thirds of the rostrocaudal extent of the intraventricular portion of the hippocampal formation. To our knowledge, the resected tissue was not analyzed histologically. The operation reduced the frequency of H. M.'s seizures, but it also had an unexpected result: It produced a severe anterograde amnesia (Scoville and Milner, 1957; Milner et al., 1968; Corkin, 1984) that has lasted to the present.

Neurological findings in H. M. are stable and consist of a severe amnesic syndrome, anosmia (with sparing of odor detection and odor discrimination) (Eichenbaum et al., 1983), left ulnar neuropathy attributable to compression of the ulnar nerve at the elbow, peripheral neuropathy (glove and stocking sensory deficit), and cerebellar dysfunction (incoordination of movement and nystagmus on lateral gaze). He has bilateral tinnitus that may be central in origin. The peripheral neuropathy and cerebellar dysfunction probably represent side effects of phenytoin (Dilantin), an anticonvulsant medication (Theodore et al., 1987; Botez et al., 1988; Masur et al., 1989). Cerebellar atrophy typically is severe in chronically treated patients; it is related to duration of illness and to the total amount of phenytoin ingested (Botez et al., 1988). H. M. had been taking high doses of phenytoin before his operation. He continued to take phenytoin until 1984, when Tegretol was prescribed as a substitute. As early as 1962, he showed symptoms of Dilantin toxicity. He was noted to have slight unsteadiness on tandem walking and slight slowness in performing rapid alternating movements with both feet (suggesting cerebellar dysfunction) and well-developed gum hypertrophy (a common side effect of phenytoin) (Grant et al., 1988; Bekele et al., 1990). His current seizure medications include Tegretol, Mysoline, and Klonopin. He had not experienced a major motor seizure in several years until August 1994, when a high fever precipitated two such seizures. Based on previous electroencephalography (EEG) studies, he probably has petit mal attacks.

An EEG performed in 1993 showed intermittent bursts of generalized spike and wave and polyspike activity, which were of maximal amplitude over the fronto-temporal regions bilaterally. The bursts lasted between 1 and $4 \mathrm{sec}$ and were more frequent and of longer duration with hyperventilation. The runs of spike and wave activity were less prolonged than they 

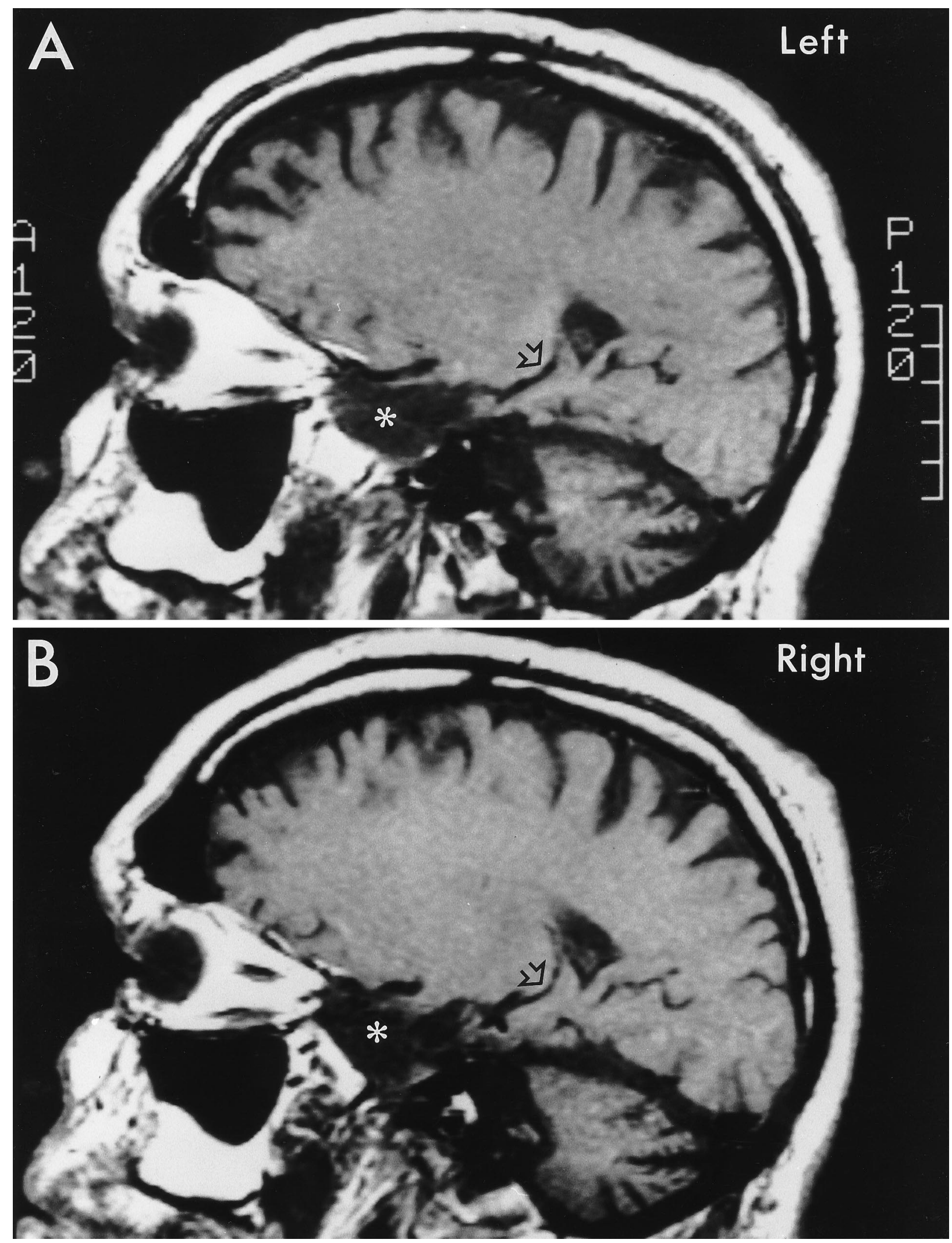

Figure 3. T1-weighted parasagittal sections from the left $(A)$ and right $(B)$ sides of H. M.'s brain. The resected portion of the anterior temporal lobes is indicated bilaterally with an asterisk. The remaining portion of the intraventricular portion of the hippocampal formation is indicated with an open arrow. Scale bar (right of $A), 5 \mathrm{~cm}$ in $1 \mathrm{~cm}$ increments. Approximately $2 \mathrm{~cm}$ of preserved hippocampal formation is visible bilaterally. Note also the substantial cerebellar degeneration obvious as enlarged folial spaces. 

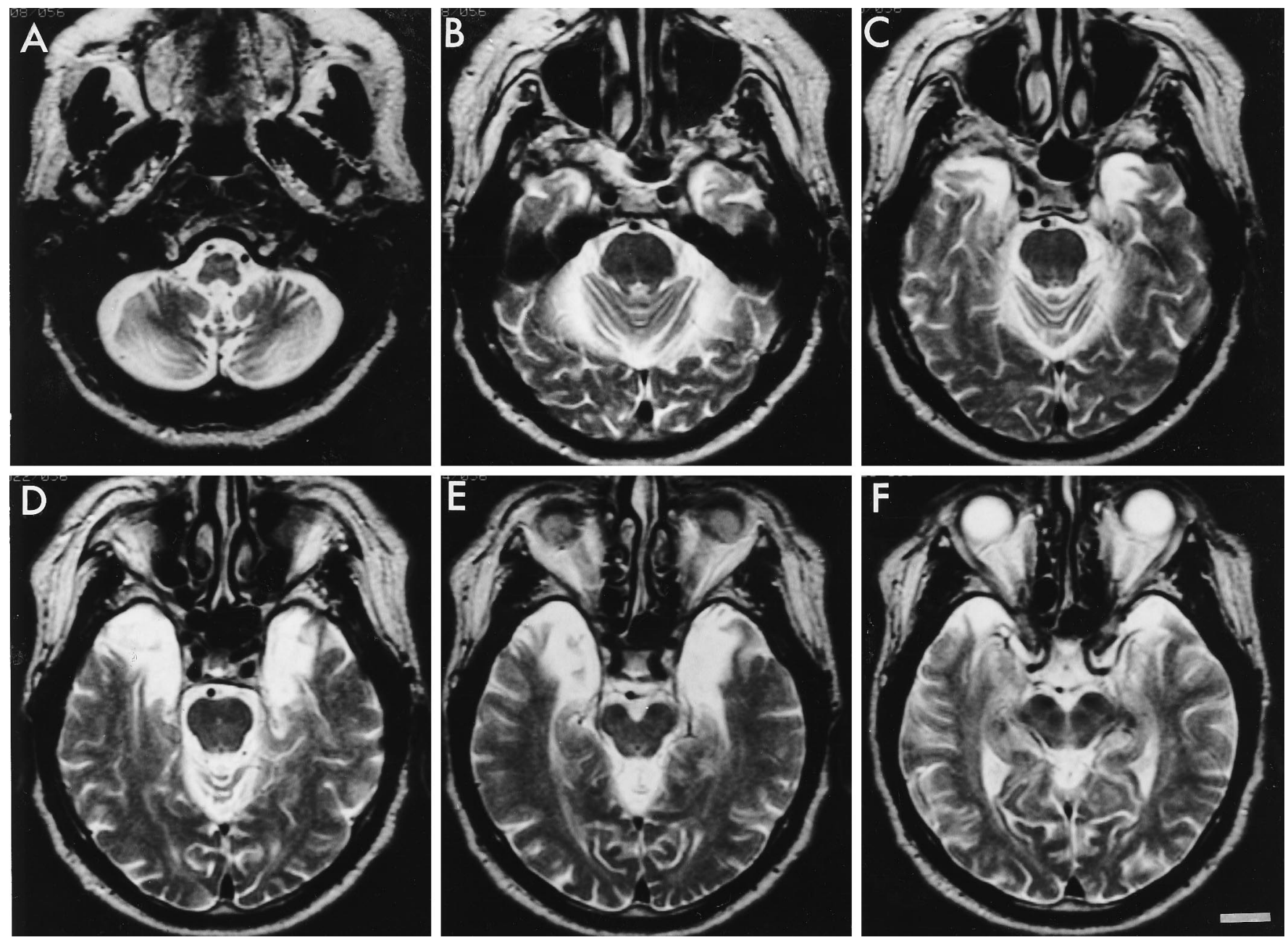

Figure 4. T2-weighted axial sections indicating the extent of the anterior temporal lobe resection bilaterally (bright signal areas in $C-F$ ). Cerebellar atrophy is obvious in $A$ and $B$ as increased fluid space (bright signal) surrounding the cerebellum and within folial spaces. Scale bar (shown in $F$ ), $2 \mathrm{~cm}$.

had been in 1984. There was no clinical accompaniment to the epileptiform activity.

H. M. had psychiatric evaluations in 1982 and 1992, using the Eysenck Personality Inventory, Profile of Mood States, Symptom Questionnaire, and Beck Depression Inventory. He has also participated in psychiatric interviews on several occasions. The results of these evaluations can be summarized as follows. In self care, he is somewhat negligent and requires supervision. With respect to personality and motivation, he is socially interactive but lacks initiative. His emotions are typically blunted, but he is capable of displaying a full range of emotions. He has no libido. His insight into his condition is excellent. He is always aware that he has a memory impairment and does not confabulate to conceal it. He has no evidence of anxiety, major depression, or psychosis. From September 1986 to February 1996, he received Mellaril for intermittent irritability, which appeared to be a reaction to the noisy and hectic atmosphere of the nursing home where he lives. This medication was not administered during his stays at the MIT Clinical Research Center when he participated in research.

Figure 5. This series of T1-weighted images is arranged from rostral $(A)$ to caudal $(F)$ through the temporal lobe of $\mathrm{H}$. M. (shown on left) and of a 66-year-old man who has served as a control subject in neuropsychological studies. Sections from the control brain were selected to match as closely as possible the levels illustrated from H. M.'s brain. Images from H. M. are from the more recent three-dimensional acquisition in which $3.2 \mathrm{~mm}$ sections were reconstructed. The control brain illustrates the structures that are likely to have been eliminated in H. M.'s brain at each rostrocaudal level. $A$, The amygdala $(A)$ and entorhinal cortex $(E C)$ are heavily damaged at this level. The collateral sulcus $(c s)$ is barely visible; therefore, little of the perirhinal cortex $(P R)$ is likely to be intact at this level. $B$, This is the rostral level of the intraventricular portion of the hippocampal formation $(H)$, which is missing bilaterally in $\mathrm{H}$. M. The entorhinal cortex is also missing at this level. Because the collateral sulcus is visible, it is possible that some perirhinal cortex is intact at this level. The medial mammillary nucleus is present at this level and appears to be slightly shrunken in $\mathrm{H}$. M. $C$, This is a rostral level through the body of the intraventricular hippocampal formation. Most of the hippocampal formation, including the entorhinal cortex, is missing at this level in H. M. $D$, A level through the caudal body of the hippocampus. Some tissue is visible bilaterally in the region of the hippocampus in H. M., although it is clearly shrunken compared with the normal control subject. This level is typically located caudal to the entorhinal cortex, which is replaced with parahippocampal cortex (areas TF and TH). E, This level is at the caudal pole of the hippocampus. There is no overt damage to the medial temporal lobe at this level. The intraventricular portion of the hippocampal formation does look shrunken, however, relative to the normal control subject. The fimbria $(f)$ is visible in the normal control subject and in H. M. F, This level is caudal to the hippocampal formation and is presented primarily to illustrate the substantial atrophy of the cerebellum $(\mathrm{Cer})$ in $\mathrm{H}$. M. In the normal control subject, the cerebellar cortex extends to the limit provided by the tentorium cerebelli. In H. M., there is a substantial fluid-filled gap between the cerebellar cortex and the tentorium. Note throughout that H. M.'s cerebral cortex demonstrates relatively little sulcal widening and that sulcal widening is more pronounced in the cognitively normal control subject. Figure continues. 

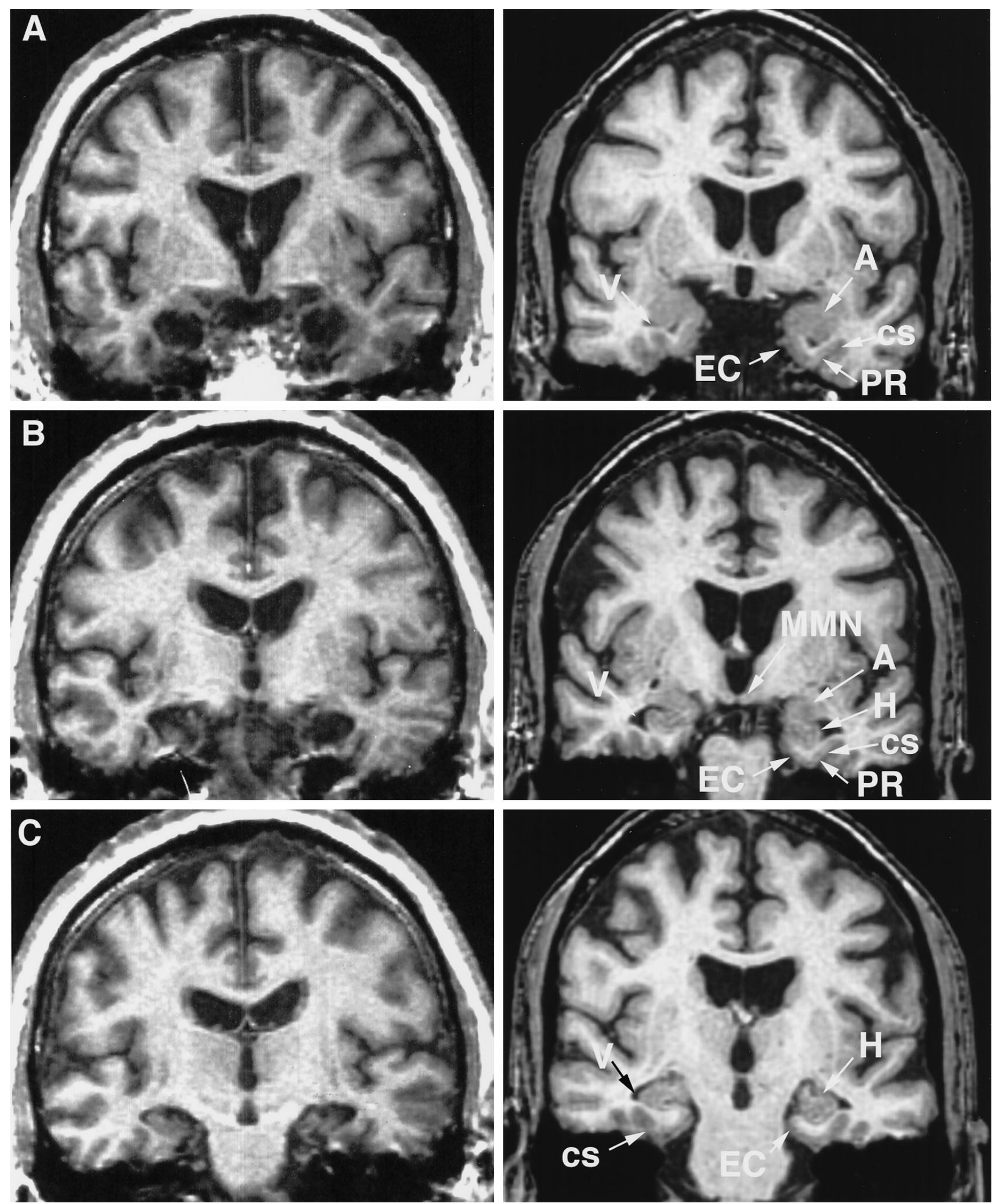

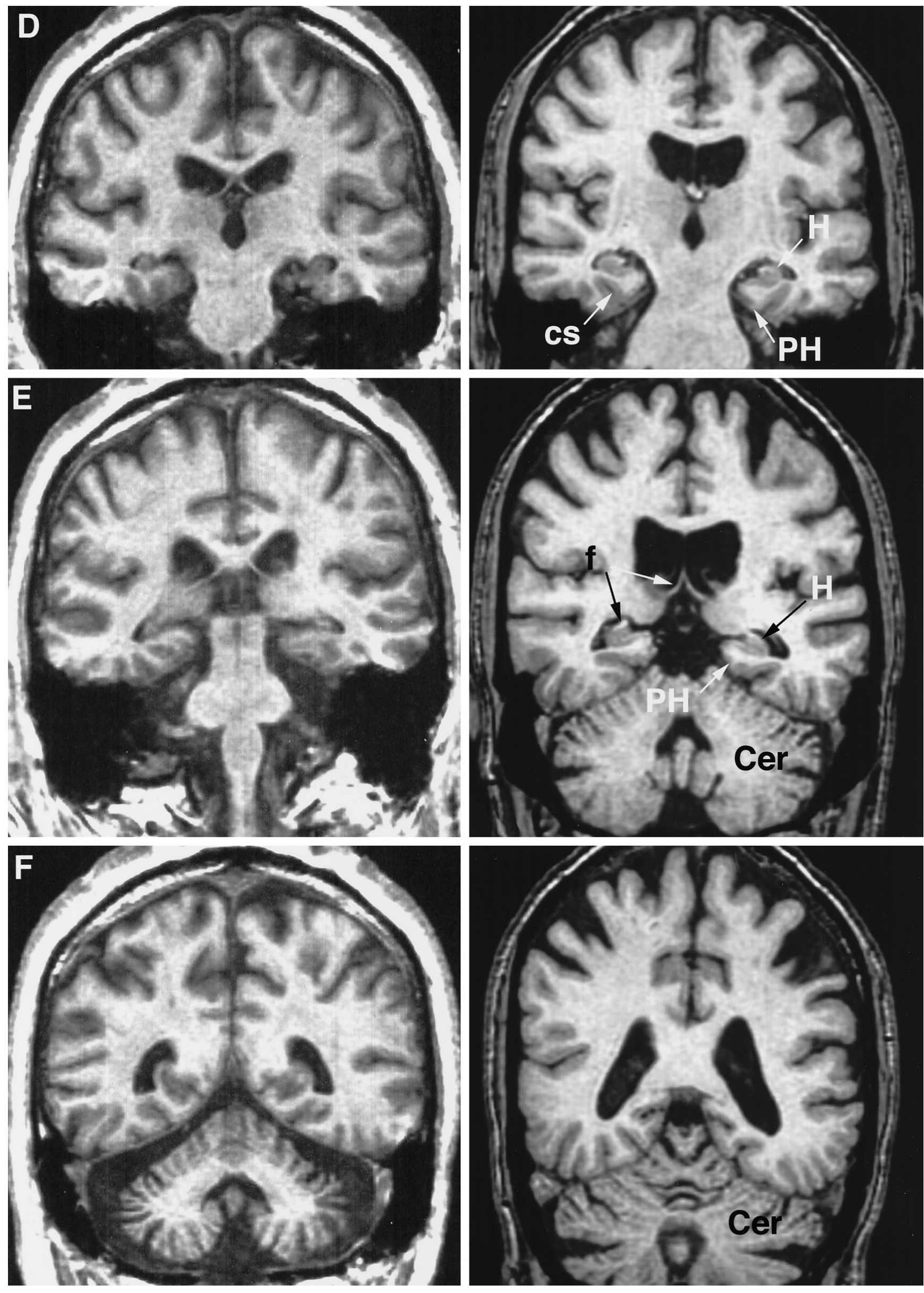

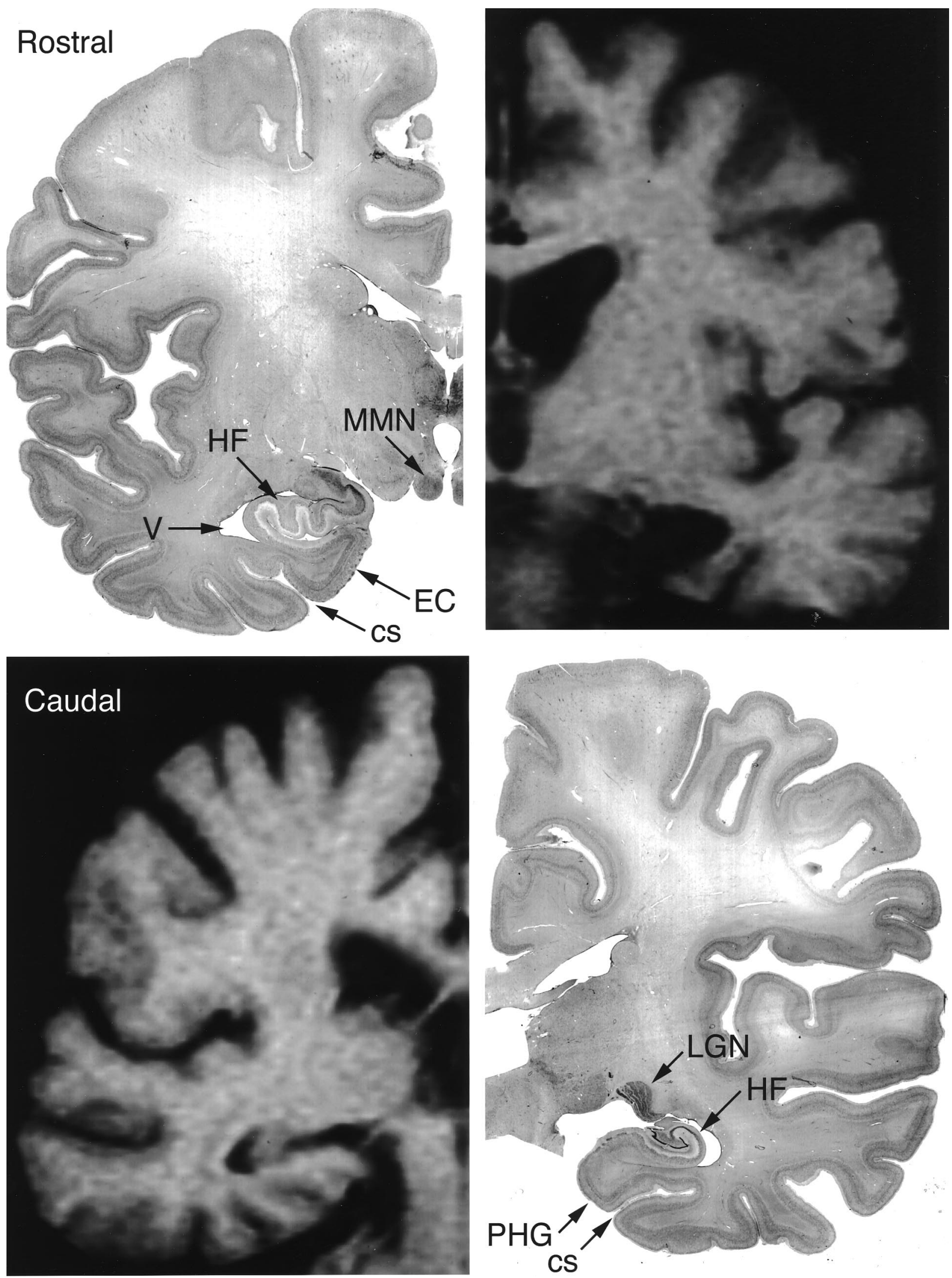

Figure 6. Nissl-stained sections from a control brain and comparable MRI sections from H. M.'s scan at rostral (top) and caudal (bottom) levels through the hippocampal formation. H. M.'s left hemisphere is shown at the rostral level, and the right hemisphere is shown at the caudal level. The Nissl-stained sections provide information on the normal appearance of the removed (Rostral) portion of the hippocampal formation and the preserved (Caudal) portion. $C S$, Collateral sulcus; $E C$, entorhinal cortex; $H$, hippocampus; $L G N$, lateral geniculate nucleus; $M M N$, medial mammillary nucleus; $P H G$, parahippocampal gyrus; $V$, ventricle. 
In 1992, 6 months before the imaging studies reported here were performed, H. M. was given the Wechsler-Bellevue Scale, Form I, and the Wechsler Memory Scale, Form II. His age-corrected scores on the Wechsler-Bellevue were Verbal I.Q., 102.7; Performance I.Q., 122.8; and Full Scale I.Q., 110.4. His Memory Quotient was 73. The 37 point discrepancy between the Wechsler-Bellevue and Wechsler Memory Scale scores indicates a severe amnesia. In contrast, he scored in the normal range on numerous standard measures of frontal lobe, language, and visuospatial function (for details, see Corkin, 1984), reflecting the integrity of the neocortex and its subcortical connections. These scores may be depressed somewhat by the actions of antiepileptic medications, which are known to impair cognition, particularly when multiple anticonvulsants are administered (Vining, 1987).

MRI analysis. Before 1992, we were reluctant to perform MRI on $\mathrm{H}$. M., because we feared that the procedure would heat up or move three clips placed on the dura mater at the time of operation. Enhanced computed tomography showed that these clips were far removed from any arteries. They were used to coagulate veins running within the dura at the margin of the resection. Venous structures thrombose within days after being clipped, and the clips are typically surrounded by fibrous tissue within a few years after placement. Thus, even if the clips were susceptible to a magnetic field, the effect on the surrounding brain would be minimal. After extensive consultation with colleagues in neurosurgery and neuroradiology, it was determined that the procedure would be safe for H. M. for two reasons. First, the dural clips were nonmagnetic and therefore would not move during exposure to a magnetic field. Second, the clips would not heat up beyond the temperature that the brain reaches in a febrile state. Our sources of information were as follows. We learned from Dr. Benjamin Whitcomb, a neurosurgeon and Scoville's former partner, that the dural clips used in H. M. and other patients were purchased from Codman and Shurtleff in Randolph, MA. A telephone call to Codman and Shurtleff revealed that the dural clips made in 1953 were either silver or tantalum, i.e., nonmagnetic. We also consulted Dr. David Piepgras, Chair of the Task Force on Clips and Clip Appliers, a subcommittee of the Joint Committee on Devices and Drugs of the American Association of Neurological Surgeons and the Congress of Neurological Surgeons. Dr. Piepgras stated that in the case of dural clips from 1953, there should be no risk of movement, deflection, or overheating during exposure to magnetic fields such as those encountered in MRI. Additionally, a review of more than 40 published studies by Shellock and Curtis (1991) stated that

None of the six hemostatic vascular clips evaluated were [sic] attracted by static magnetic fields used for MR imaging, up to field strengths of 1.5 T. These hemostatic clips are made from nonferromagnetic materials and, therefore, do not present a risk to patients during MR imaging. Patients with each of the hemostatic vascular clips listed have undergone imaging safely with a $1.5 \mathrm{~T}$ MR imager at our institution ( p 547).

With our concerns for the safety of H. M. eliminated, MRI was performed in May 1992, using a 1.5-Tesla Signa System (General Electric, Milwaukee, WI) scanner at the Brigham and Women's Hospital. T1weighted coronal images [repetition time (TR) 550; echo time (TE) 16] were acquired with a $5-\mathrm{mm}$-slice thickness and a $1 \mathrm{~mm}$ interval between slices [256 $\times 192$ matrix; number of excitations (NEX) 1.0; field of view (FOV) 22]. A sagittal series of T1-weighted images (TR 600; TE 19) was acquired with a $4 \mathrm{~mm}$ slice thickness and a $1 \mathrm{~mm}$ gap between sections $(256 \times 192$ matrix; NEX 1.0; FOV 24). A T2-weighted series of axial images (TR 2500; TE 90) was acquired with a 5-mm-slice thickness and no gap between slices $(256 \times 192$ matrix; $1.0 \mathrm{NEX}$; FOV 22). In a second scanning session conducted in August 1993 at the Massachusetts General Hospital Nuclear Magnetic Resonance Center, a three-dimensional acquisition with $3.2 \mathrm{~mm}$ slices using an SPGR/35 sequence $(256 \times 256 ; 1.0$ NEX; FOV 25) was undertaken. Both scanning sessions produced similar results as to the extent of the temporal lobe lesion. The figures show images from both series. Figure legends describe the imaging parameters.

\section{RESULTS}

\section{Review of the surgical procedure}

Scoville's approach to the temporal lobes was made through bilateral $3.8 \mathrm{~cm}$ supraorbital trephine holes; the skull defects resulting from this approach are visible in the MRI (see Fig. $2 M, O)$. Scoville described his "medial temporal lobotomy" pro- cedure, which had been performed in a number of schizophrenic patients, in the following way (Scoville et al., 1953):

After exposing both the tip and medial surface of the temporal lobes, a cortical incision is made just anterior to the middle cerebral vessels under the midpoint of the sphenoidal ridge so as to bisect the tips of the temporal lobes. It is necessary to retract the middle cerebral vessels both posteriorly and superiorly with the narrow flat spatula and to remove fractionally by fine suction the entire medial tips of the temporal lobes. It is not necessary to coagulate vessels with the exception of an occasional small subpial vein on the floor of the temporal fossa. After resecting the medial tips of the lobes, it is necessary to elevate the middle cerebral vessels even higher and remove subpially by suction the grey and white matter situated medial to the temporal horns. This includes the amygdaloid nucleus, periamygdaloid cortex and anterior portion of the hippocampus. The resection is carried $5 \mathrm{~cm}$. posteriorly from the tips of the temporal lobes and $3 \mathrm{~cm}$. from the tips of the temporal horns which lie approximately level with the 3rd nerve exit into its dural ridge. The resection includes the medial wall of the anterior $3 \mathrm{~cm}$. of the temporal horns and exposes the choroid plexus within the horns. It extends vertically down to the floor of the temporal fossa and superiorly to the upper limits of the lobe. Posteriorly, the resection emerges in the subpial space approximately level with the posterior surface of the peduncles and posterior edge of the petrous ridge. The medial landmarks from front backwards are the anterior clinoid, the carotid artery, the 3rd nerve and optic tracts, the peduncle and posterior cerebral artery. These structures are protected by keeping subpially thruout [sic] the fractional suction resection, but it is necessary to continually insert the very narrow spatula extrapially and visualize the peduncles and optic tracts as one progresses in order to prevent penetrating the pia and damaging these structures. It is to be noted that the peduncles constitute both the medial and superior surface of the temporal lobes (pp 353-354).

In the paper documenting the surgical procedure used with H. M. (Scoville and Milner, 1957), Scoville first described operative procedures performed in 30 psychiatric patients. In one group, the resections "were limited to the uncus and underlying amygdaloid nucleus" (p 11). In a second group, larger resections were carried back $5 \mathrm{~cm}$ or more from the tips of the temporal lobes and "encroached... upon the anterior hippocampus" ( $\mathrm{p}$ 11), as described above. In a single psychiatric case, "all tissue mesial to the temporal horns for a distance of at least $8 \mathrm{~cm}$ posterior to the temporal tips was destroyed, a removal which presumably included the anterior two-thirds of the hippocampal complex bilaterally." (p 11). It was this more extensive resection that was performed in H. M. "An equally radical bilateral medial temporal lobe resection was carried out in one young man (H. M.) with a long history of major and minor seizures..." (p 11).

The present findings update this description with precise anatomical localization of the surgical lesion. By our estimation, and consistent with previous analyses of the human hippocampal formation (Amaral and Insausti, 1990), the entire rostrocaudal distance from the temporal pole to the caudal limit of the hippocampal formation in H. M. is $\sim 7.0 \mathrm{~cm}$. Thus, had Scoville actually removed $8 \mathrm{~cm}$ of mesial tissue, the resection would have continued well into the calcarine cortex. The diagram in the Scoville and Milner paper pictured a resection 
that appeared to extend caudal to the hippocampal formation (Fig. 1, left). This illustration is at variance with Scoville's written description (which likely represents his best estimate) depicting the resection as sparing at least one third of the caudal hippocampus. The MRI analysis provided evidence of a smaller lesion (Fig. 1, right), which is not entirely consistent either with Scoville's figure or with his written description. The right side of Figure 1 provides a modification of the original Scoville illustration that is more consistent with the MRI findings.

\section{MRI analysis}

\section{Terminology}

Before presenting the results of H. M.'s MRI analysis, it is necessary to define medial temporal lobe terminology. The rostral pole of the medial temporal lobe (Brodmann area 38) is made up of cortex that closely resembles perirhinal cortex (areas 35 and 36) (Insausti et al., 1994).

The temporal polar portion of the perirhinal cortex is continuous with the ventrally situated portion of the perirhinal cortex, which lines the banks of the collateral sulcus. The perirhinal cortex extends approximately to the rostral limit of the lateral geniculate nucleus and is replaced caudally by the parahippocampal cortex (areas TF and TH). Medially, the amygdaloid complex lies caudal to the temporal polar cortex, and the hippocampal formation is caudal to the amygdala.

The hippocampal formation is made up of four components: the dentate gyrus, hippocampus, subicular complex, and entorhinal cortex. The portion of the hippocampal formation that lies in the floor of the lateral ventricle (the portion that we refer to as the intraventricular portion) is made up of the dentate gyrus, hippocampus, and subicular complex. The entorhinal cortex lies ventral to the intraventricular portion of the hippocampal formation and extends for $\sim 1 \mathrm{~cm}$ anterior to the anterior limit of the lateral ventricle. Here the entorhinal cortex is medially and ventrally adjacent to the amygdaloid complex. In a normal, adult brain, the distance from the tip of the temporal pole to the most caudal aspect of the hippocampal formation is $\sim 7.5 \mathrm{~cm}$. The normal extent of the intraventricular portion of the hippocampal formation is $\sim 4 \mathrm{~cm}$. (For additional details on the human hippocampal formation, see Amaral and Insausti, 1990.)

\section{General appearance of the brain}

The rostrocaudal length of the brain is $\sim 14-15 \mathrm{~cm}$, and the rostrocaudal extent of the temporal lobe (from the temporal pole to the splenium of the corpus callosum) is $\sim 7 \mathrm{~cm}$. The cortical surface generally appears normal for a 66-year-old subject and, other than the temporal lobe and cerebellar alterations described below, there is no indication of diffuse cortical or subcortical brain pathology.

\section{Temporal lobe findings}

In general, the MR images of H. M.'s resection matched Scoville's description. The only major discrepancy was in the rostrocaudal extent of the ablation. Scoville had indicated that the resection extended $\sim 8 \mathrm{~cm}$ rostrocaudally. Using a liberal criterion of including within the ablation those levels with even minor damage (as in the left hemisphere shown in Fig. 2D), the rostrocaudal extent of the ablation on the left is $\sim 5.4 \mathrm{~cm}$ and on the right is $\sim 5.1 \mathrm{~cm}$. The resection was evident from the rostral pole of the temporal lobe (Figs. $2 K, L, 4 D, E$ ) and remained medial to the lateral wall of the temporal horn of the lateral ventricle. For much of its rostrocaudal extent, the resection extended to the ventral surface of the temporal lobe. However, unlike the illustration depicting the surgical report (Fig. 1, left), the edge of the resection had an oblique, ventromedial orientation and thus spared much of the cortex on both banks of the collateral sulcus (Fig. 2E-I).

The surgical resection produced a bilaterally symmetrical lesion of the medial temporal lobe. Although there were minor differences in the extent of lesion in the two hemispheres, the resections of the left and right hemispheres were remarkably similar. A series of T1-weighted coronal images through the frontal and temporal lobes illustrates the extent of the ablation (Fig. 2). Sagittal T1-weighted images through the body of the hippocampus (Fig. 3) show the extent of the ablation in the rostral temporal lobe and the amount of residual intraventricular hippocampal formation. The axial T2-weighted images (Fig. 4) also show the temporal lobe lesion as well as the dramatic cerebellar atrophy.

The ablation damaged extensively the anterior medial temporal polar cortex bilaterally. The subcortical white matter associated with the most anterior portions of the superior, middle, and inferior temporal gyri may have also been compromised by the resection (Fig. 2I,J). The ablation was extensive at levels at which the amygdaloid complex would be expected (Figs. $2 G, H, 3$ ), and most of the amygdaloid complex is missing. Only a thin rim of dorsomedially situated amygdaloid tissue is evident at these levels. This region would contain remnants of the periamygdaloid and piriform cortices and the anterior cortical nucleus. At more caudal levels (Fig. $2 G$ ), the most dorsal portion of the amygdaloid complex, which consists in part of the central nucleus, appears to be intact bilaterally. Scoville clearly intended to spare this dorsal amygdaloid region, because he was concerned about damaging the numerous blood vessels that perforate the overlying substantia innominata (anterior perforated substance). The cholinergic cell groups of the basal nucleus of Meynert are embedded in this region, and this portion of the basal forebrain appears to be spared. At levels through the amygdaloid complex, the lesion extended obliquely with a medially directed inclination to the ventral surface of the temporal lobe. The underlying rostral entorhinal cortex appeared to be completely removed. A key finding was that the collateral sulcus was clearly visible at these levels (Fig. $2 E-G$ ), and thus, the ventrocaudal perirhinal cortex (areas 35 and 36), which occupies both banks of the collateral sulcus, appears to be at least partially intact at these levels. The laterally adjacent fusiform gyrus was entirely intact.

Just behind the amygdaloid complex in the normal brain is the uncal portion of the hippocampal formation, consisting of an intricately folded allocortex, and the subjacent entorhinal cortex. The intraventricular portion of the hippocampal formation is typically first visible in the normal brain at approximately the rostrocaudal level at which the mammillary nuclei are apparent (Fig. $2 F$ ). In H. M., the uncal portion and this rostral portion of the body of the hippocampal formation was completely removed bilaterally. Virtually all of the entorhinal cortex, bilaterally, was either removed or damaged extensively. Posterior portions of the intraventricular hippocampal formation, however, were spared (Fig. $2 C-E$ ). The spared portion of the hippocampus was appreciated best in the sagittal images (Fig. 2). Although it was difficult to estimate with certainty the amount of residual hippocampal formation, estimates from the 5-mm-thick slices and from the 3.2 $\mathrm{mm}$ contiguous series indicated that these remnants accounted for $\sim 1.9-2.2 \mathrm{~cm}$ of hippocampal tissue. Because the intraventricular extent of the hippocampal formation in a normal human brain is $\sim 4 \mathrm{~cm}$ in rostrocaudal extent (Amaral and Insausti, 1990), the 
residual hippocampal formation in $\mathrm{H}$. M. thus approximated $50 \%$ of the normal intraventricular extent. It also should be noted that although the hippocampal formation was clearly visible at these caudal levels, it appeared to be somewhat atrophic bilaterally; thus, its functional integrity cannot be assured. This atrophy could be attributed to any number of factors, including loss of neuropil after extrinsic deafferentation, loss of associational connections from rostral hippocampal levels, or even hippocampal sclerosis related to H. M.'s epilepsy. The fimbria and fornix, as expected, appeared somewhat thin.

At the posterior levels where the hippocampal formation was clearly present (Fig. 2D,E), the parahippocampal gyrus continued to be somewhat compromised by the ablation. Figure $2 D$ illustrates a level through the lateral geniculate nucleus, which is at or posterior to the caudal border of the entorhinal cortex (Van Hoesen, 1982). The ablation extended slightly caudal to this level on the left, and thus may have invaded the rostral portions of the posterior parahippocampal gyrus. The lesion extended slightly farther caudally in the left hemisphere than in the right (Figs. 2D, $4 E$ ) and ended completely before the posterior limit of the hippocampal formation bilaterally (Fig. $2 C$ ). It would appear, therefore, that areas TF and $\mathrm{TH}$ of the parahippocampal cortex received only minor damage.

Because the ablation maintained its medial position throughout its rostrocaudal extent, there appeared to be essentially no invasion of the lateral temporal neocortex (other than at the temporal pole). There was no evidence of injury to the optic radiations, to the visual cortex in the depths of the calcarine sulcus, or to the more lateral occipital cortices (Brodmann areas 17, 18, and 19).

In summary, the temporal lobe lesions included the medial temporal polar cortex, most of the amygdaloid complex, and all of the entorhinal cortex bilaterally (Figs. 5, 6). In addition, the anterior $2 \mathrm{~cm}$ (of a total $4 \mathrm{~cm}$ rostrocaudal distance), approximately, of the dentate gyrus, hippocampus, and subicular complex was removed. The posterior $2 \mathrm{~cm}$, approximately, of these fields was visible but appeared atrophic. Because the collateral sulcus and the cortex lining its medial bank were also visible throughout much of the temporal lobe, at least some of the ventral perirhinal cortex, which is located along the banks of this sulcus, appeared to be intact. The cortices of the posterior parahippocampal gyrus (areas TF and TH) appeared to be only slightly damaged, and only at rostral levels of these fields. The lingual and fusiform gyri, located lateral to the collateral sulcus, were intact.

\section{Brain regions outside the temporal lobes}

The most noticeable nontemporal lobe region of pathology was in the cerebellum (Figs. $2 A, 4 A, 5$ ). There was marked and diffuse atrophy of the vermis and hemispheres, evident in Figure $4 A$ as high-signal, CSF-filled subarachnoid space.

The frontal, parietal, and occipital lobe cortices had a generally normal appearance. Neocortical atrophy was slight and consistent with H. M.'s age (Fig. 5). There was no obvious lesion in the orbital or ventromedial frontal cortex that could be attributed to the surgical elevation of these areas for visualization of the temporal lobes. Although regions of the dorsolateral frontal cortex located deep to the defects of the trephine holes appeared to have somewhat prominent sulcal spaces (Fig. 2M-O), it was unclear whether this damage resulted from trauma during the neurosurgical procedure. The mediodorsal nucleus of the thalamus (Fig. $2 D, E)$ demonstrated no clear alterations, but the mammillary nuclei (Figs. $2 F, 5$ ) were reduced in size.

\section{DISCUSSION}

For the first time, we have been able to evaluate the neurosurgical resection in $\mathrm{H}$. M., perhaps the most studied person in behavioral neuroscience. These investigations were driven by the need to determine precisely which medial temporal lobe regions were included in his resection and which may be responsible for his amnesic syndrome. It was particularly important to conduct this study at this time because experimental animal studies recently have questioned the role of the hippocampus in memory function (Mishkin and Murray, 1994). This initial MRI study has confirmed and extended conclusions from Scoville's surgical report. The following discussion focuses on two issues: (1) the anatomical substrates for explicit or declarative memory in humans, and (2) the correspondence between the critical neural substrates in amnesic patients and in primate models of amnesia.

\section{Anatomical substrates for explicit/declarative memory in humans}

The anterograde amnesia in H. M. is profound (Scoville and Milner, 1957; Milner et al., 1968; Corkin, 1984) and, as a result, he has become the yardstick against which the severity of other amnesias are judged. In fact, most other published cases of medial temporal lobe amnesia demonstrate a less severe form of memory impairment. What is it about H. M.'s lesion that has caused such a profound memory impairment? H. M.'s resection eliminated the entire medial temporal polar cortex (Filimonoff area TG, Brodmann area 38), virtually the entire amygdaloid complex, essentially all of the entorhinal cortex, and at least half of the intraventricular portion of the hippocampal formation. Because the entorhinal cortex was eliminated, the remaining caudal portion of the hippocampal formation is devoid of most of its input from sensory and high-order cortices (Van Hoesen, 1982; Amaral et al., 1987; Insausti et al., 1987). By contrast, cholinergic innervation from the basal forebrain is probably largely intact (Alonso and Amaral, 1995). It is likely that the memory impairments in other cases (Scoville and Milner, 1957) were milder or transient, because a substantial portion of the hippocampal formation was spared.

Penfield and Milner's patient, P. B., (Penfield and Milner, 1958), provides additional evidence that partial sparing of the posterior hippocampus and sparing of the parahippocampal gyrus are not sufficient to maintain normal memory function. P. B. received a two-stage unilateral temporal lobe resection for the alleviation of epilepsy. In the first stage, performed on August 14, 1946 , the anterior $4 \mathrm{~cm}$ of the left temporal (lateral) neocortex was resected; the hippocampal formation and amygdala were left intact. In a second operation, performed on September 28, 1951, Penfield removed the left temporal polar cortex, amygdaloid complex, and anterior half of the hippocampal formation. After this operation, the patient became severely amnesic and was still profoundly amnesic when retested in 1962 (Corkin, 1965). His general intelligence, in contrast, was remarkably preserved, and he had no aphasia (Penfield and Mathieson, 1974). This patient ultimately came to autopsy, and his brain underwent histological examination (Penfield and Mathieson, 1974). The left surgical resection removed all of the cross-sectional extent of the anterior temporal lobe, i.e., it was more extensive laterally than in H. M. As in H. M., $\sim 22 \mathrm{~mm}$ of the caudal hippocampal formation remained on the left, and it had a generally normal histological appearance, except for gliosis in the alveus and fimbria. On the right, the anterior temporal lobe and amygdala appeared normal. However, the right hippocampus was shrunken, with substantial cell loss in the pyramidal cell layer and dentate gyrus (Penfield and 
Table 1. Relation between extent of medial temporal-lobe lesion and severity of amnesia as measured by the difference between the Full Scale I.Q. (F.S. I.Q.) and the Memory Quotient (M.Q.). (Normal subjects show no significant difference.)

\begin{tabular}{|c|c|c|c|c|}
\hline Subject & Lesion & F.S. I.Q. & M.Q. & I.Q.-M.Q. \\
\hline H. M. & $\begin{array}{l}\text { Medial temporal pole (rostral perirhinal cortex), most of amygdaloid complex, anterior } 2-2.5 \mathrm{~cm} \text { of dentate } \\
\text { gyrus, hippocampus, and subicular complex bilaterally (age corrected) }\end{array}$ & 102.7 & 73 & 37 \\
\hline P. B. & $\begin{array}{l}\text { Left anterior temporal lobectomy including left temporal pole, most of amygdaloid complex, and anterior } \\
\text { half of hippocampal formation. Right hippocampus shrunken with diffuse cell loss in hippocampus and } \\
\text { dentate gyrus }\end{array}$ & 125 & 97 & 28 \\
\hline R. B. & $\begin{array}{l}\text { CA1 field of hippocampus bilaterally, with minimal cell loss in subiculum, CA3 field, and anterior } \\
\text { amygdaloid area }\end{array}$ & 111 & 91 & 20 \\
\hline
\end{tabular}

Mathieson, 1974). The right-side pathology indicated epilepsyassociated hippocampal sclerosis (Margerison and Corsellis, 1966), i.e., diffuse cell loss in the hippocampus and dentate gyrus, with relatively complete preservation of the subicular complex and parahippocampal cortex (including the entorhinal cortex).

Several conclusions can be drawn from P. B.'s case. As in H. M., the preserved hippocampus on the left, even though histologically normal, was not sufficient to support normal memory function. Amnesia in P. B. may have occurred because the second resection of the left anterior temporal lobe removed most, if not all, of the entorhinal cortex and thus eliminated much of the sensory information to the residual intraventricular hippocampal formation. This case also provides evidence that a clinically significant amnesic syndrome is obtained even if the bilateral component of the lesion is restricted to the hippocampus proper and dentate gyrus. Amnesia in P. B., however, was less severe than that in H. M. (Table 1, Fig. 6) (see also Corkin, 1965, p 347). As experimental studies in primates now indicate, it may be necessary for bilateral lesions to include the entorhinal and/or perirhinal cortices (as in H. M.) to obtain an amnesic syndrome as severe as that in H. M. (Meunier et al., 1993; Zola-Morgan et al., 1993).

A similar conclusion was reached from the analysis of patient R. B. (Zola-Morgan et al., 1986). He suffered an ischemic episode that produced a bilaterally symmetrical lesion largely confined to the CA1 field of the hippocampus. Although this lesion produced a clinically significant anterograde amnesia, it was milder than that in $\mathrm{H}$. M. (Table 1). Thus, the results from P. B. and R. B. support the conclusion that a bilateral lesion of the hippocampal formation alone produces a clinically significant amnesic syndrome in humans. However, if the bilateral lesion includes other medial temporal lobe structures, such as the temporal polar cortex, perirhinal cortex, and entorhinal cortex (as in H. M.), the amnesic syndrome is much more severe than that resulting from a selective hippocampal lesion. The relative importance of each of these structures in humans for normal memory function, as well as for the precise cognitive processes to which they contribute, still needs to be ascertained. By one view, each of these regions performs qualitatively similar functions, and the progressive severity of amnesia that is observed with increased damage is attributable to loss of the capacity to perform the primary function of this region (Zola-Morgan et al., 1994). An alternative view is that each of these brain regions contributes differentially to memory function (Murray, 1992; Gaffan, 1992a,b,c, 1994; Eacott et al., 1994; Eichenbaum et al., 1994; Meunier et al., 1996), perhaps by using different cognitive strategies, and the progressive amnesia is attributable to the elimination of alternate means for forming memories. Because pathology rarely invades a singular, neuroanatomical region in the medial temporal lobe, the ultimate resolution of this issue may rely on other methods such as functional brain imaging.

The findings from H. M., P. B., and R. B. also allow one to dismiss the "temporal stem" hypothesis of medial temporal lobe amnesia (Horel, 1978). Horel speculated that the human amnesic syndrome was not attributable to damage of the hippocampal formation, but rather to damage of the white matter, the temporal stem, located immediately dorsal to the hippocampal formation. In none of the three patients discussed above, however, was the temporal stem directly damaged bilaterally, nor were most of the neocortical regions that contribute fibers to the temporal stem damaged bilaterally. Further, because the caudal half of the hippocampus is spared in H. M. (as it was in P. B.) and because the fornix and mammillary nuclei are also spared in H. M., the subcortical connections of the hippocampus do not appear to be sufficient to sustain normal memory function. This finding would argue against Gaffan's view that these connections, rather than hippocampal cortical connections, are primarily responsible for the role of the hippocampal formation in memory (Gaffan, 1992c). The bulk of evidence, therefore, rests on the hippocampus and associated cortical regions as the prime substrates for medial temporal lobe amnesia.

What anatomical considerations would explain the profound amnesia in H. M.? Some of the regions removed in H. M., such as the medial temporal polar cortex and entorhinal cortex, have not been studied thoroughly in the human brain. In the nonhuman primate, however, neuroanatomical and behavioral studies have converged to indicate that these regions play a role independent of the hippocampal formation in memory function. A point of terminological clarification must be made. In the macaque monkey, much of what was previously called either Brodmann area 38 or Bonin and Bailey area TG appears to have cytoarchitectonic and connectional similarities with the remainder of the perirhinal cortices (Amaral et al., 1987; Suzuki et al., 1994a,b). In the human brain as well, much of what has been labeled area 38 has cytoarchitectonic similarities with the more ventrocaudally situated perirhinal cortex that lies along the banks of the collateral sulcus. Thus, in H. M., the resection appears to have included rostral levels of the perirhinal cortex but has left intact some of the caudal portion of this region.

The perirhinal and parahippocampal cortices are at one end of a chain of feedforward projections from unimodal and polymodal cortical areas (Mesulam, 1982; Van Hoesen, 1982; Pandya and Yeterian, 1985; Freedman et al., 1986; Tranel et al., 1988; Suzuki and Amaral, 1990, 1994a; Webster et al., 1991), and, in turn, provide $\sim 60 \%$ of the cortical input to the entorhinal cortex (Insausti et al., 1987). The entorhinal cortex then forwards this sensory information to the hippocampal formation via the perforant path (Witter and Amaral, 1991).

Several sources of evidence indicate that the perirhinal and/or entorhinal cortices may play a critical role in human memory. First, studies of patients with unilateral anterior temporal lobec- 
tomy demonstrate that small hippocampal excisions are less damaging to memory performance than are large excisions (Milner, 1980; Milner et al., 1985). Large hippocampal removals, i.e., those that extend caudal to the uncus, eliminate the whole entorhinal cortex and thus interrupt cortical input to the hippocampal formation. Small hippocampal removals, in contrast, spare some of the entorhinal projections to residual hippocampus that are apparently sufficient to support residual memory function. Second, selective amygdala-hippocampectomy, which encroaches on entorhinal and perirhinal cortex but spares the lateral temporal lobe neocortex (Yasargil et al., 1993), impairs memory test performance to the same extent as does unilateral anterior temporal lobectomy with encroachment on the hippocampus (JonesGotman et al., 1997).

\section{Correspondence between the critical neural substrate in amnesic patients and in primate models of amnesia}

Early primate models of human medial temporal lobe amnesia emphasized the role of the hippocampal formation and amygdaloid complex. Specifically, monkeys with the hippocampus, amygdala, and surrounding cortex removed were impaired on several recognition memory tasks (Mishkin, 1978; Zola-Morgan et al., 1982; Murray and Mishkin, 1984; Phillips and Mishkin, 1984; Saunders et al., 1984; Zola-Morgan and Squire, 1985). To determine which areas within the medial temporal region are critical for normal memory performance, recent studies have focused on the effects of small lesions restricted to (1) the hippocampus, (2) amygdala, (3) entorhinal cortex (area 28) (Leonard et al., 1995), or (4) perirhinal cortex (areas 35 and 36) combined with parahippocampal cortex (areas TH and TF) (Zola-Morgan et al., 1989c; Suzuki et al., 1993). The results of these studies indicate that all of these anatomically linked medial temporal areas, except the amygdala, participate in recognition memory function (Murray et al., 1989; Zola-Morgan et al., 1989a,b,c, 1994; Meunier et al., 1993) (but see Murray, 1991). Although a significant memory impairment is seen when only the hippocampus, dentate gyrus, and subicular complex are included in the lesion (the H lesion) (Clower et al., 1991; Beason-Held et al., 1993; Alvarez et al., 1995), the memory impairment is more severe when the caudal entorhinal and perirhinal cortices are included in the lesion (the $\mathrm{H}^{+}$ lesion) (Mahut et al., 1982; Zola-Morgan et al., 1989a), and even more severe when the perirhinal cortex is also included (the $\mathrm{H}^{++}$ lesion) (Zola-Morgan et al., 1993). Moreover, lesions restricted to the perirhinal and parahippocampal cortices (Zola-Morgan et al., 1989c; Suzuki et al., 1993) or to the entorhinal and perirhinal cortices (Meunier et al., 1993) (sparing other medial temporal lobe structures) produce memory deficits that are not only comparable in severity with those seen after bilateral medial temporal lobectomy, but also are multimodal and long-lasting (Suzuki et al., 1993). Clearly, each of the multiple areas within the medial temporal lobe region, including the hippocampal formation and the perirhinal cortex, contributes to normal memory function. It is unclear, however, whether each of these regions is performing essentially similar mnemonic tasks so that the deficit becomes more severe when more of these processing regions are removed (Zola-Morgan et al., 1994), or whether there are dissociations of function within the medial temporal lobe region (Gaffan, 1992a,b,c, 1994; Murray, 1992; Eacott et al., 1994; Eichenbaum et al., 1994; Meunier et al., 1996) so that the memory impairment becomes more severe as more strategies for task-solution are eliminated. It will be essential to conduct parallel studies in monkeys and human amnesic subjects to determine the precise cognitive function of each of these medial temporal lobe regions.

\section{Conclusions}

This MRI study has confirmed that the lesions responsible for the amnesic syndrome in H. M. are confined to the medial temporal lobe. Given the severity and permanence of the anterograde amnesia in H. M., it is clear that the remaining $2 \mathrm{~cm}$ of posterior, intraventricular hippocampal formation, approximately, (of a total rostrocaudal extent of $\sim 4 \mathrm{~cm}$ ) is not sufficient to support normal memory functions. Whether this preserved tissue is functional and capable of mediating any cognitive processes awaits the results of ongoing functional imaging studies. The severity of the memory impairment in H. M., compared with that in other amnesic patients with selective hippocampal lesions, may be related to the inclusion of portions of his entorhinal, perirhinal, and parahippocampal cortices in the medial temporal lobe removal.

\section{REFERENCES}

Alonso JR, Amaral DG (1995) Cholinergic innervation of the primate hippocampal formation. I. Distribution of choline acetyltransferase immunoreactivity in the Macaca fascicularis and Macaca mulatta monkeys. J Comp Neurol 355:135-170.

Alvarez P, Zola-Morgan S, Squire LR (1995) Damage limited to the hippocampal region produces long-lasting memory impairment in monkeys. J Neurosci 15:3796-3807.

Amaral DG, Insausti R (1990) The hippocampal formation. In: The human nervous system (Paxinos G, ed), pp 711-755. San Diego: Academic.

Amaral DG, Insausti R, Cowan WM (1987) The entorhinal cortex of the monkey. I. Cytoarchitectonic organization. J Comp Neurol 264:326-355.

Beason-Held L, Rosene DL, Moss MB (1993) Memory deficits associated with ibotenic acid lesions of the hippocampal formation in rhesus monkeys. Soc Neurosci Abstr 19:438.

Bekele G, Abebe Y, Thaimanot R (1990) Plasma level distribution, effect and toxicity of antiepileptic drugs among Ethiopian epileptics. Ethiop Med J 28:23-30.

Botez MI, Attig E, Vézina JL (1988) Cerebellar atrophy in epileptic patients. Can J Neurol Sci 15:299-303.

Clower RP, Alvarez-Royo P, Zola-Morgan S, Squire LR (1991) Recognition memory impairment in monkeys with selective hippocampal lesions. Soc Neurosci Abstr 17:338.

Corkin S (1965) Tactually-guided maze learning in man: effects of unilateral cortical excisions and bilateral hippocampal lesions. Neuropsychologia 3:339-351.

Corkin S (1984) Lasting consequences of bilateral medial temporal lobectomy: clinical course and experimental findings in H.M. Semin Neurol 4:252-262.

Correll RE, Scoville WB (1965) Effects of medial temporal lesions on visual discrimination performance. J Comp Physiol Psychol 60:175-181.

Eacott MJ, Gaffan D, Murray EA (1994) Preserved recognition memory for small sets, and impaired stimulus identification for large sets, following rhinal cortex ablations in monkeys. Eur J Neurosci 6:1466-1478.

Eichenbaum H, Morton TH, Potter H, Corkin S (1983) Selective olfactory deficits in Case H.M. Brain 106:459-472.

Eichenbaum H, Otto T, Cohen NJ (1994) Two functional components of the hippocampal memory system. Behav Brain Sci 17:449-518.

Feindel W, Penfield W (1954) Localization of discharge in temporal lobe automatism. Arch Neurol Psychiatry 72:605-630.

Freedman DP, Murray EA, O’Neill JB, Mishkin M (1986) Cortical connections of the somatosensory fields of the lateral sulcus of macaques: evidence for a corticolimbic pathway for touch. J Comp Neurol 252:323-347.

Gaffan D (1992a) Amnesia for complex naturalistic scenes and for objects following fornix transection in the Rhesus monkey. Eur J Neurosci 4:381-388.

Gaffan D (1992b) Amygdala and the memory of reward. In: The amygdala: neurobiological aspects of emotion, memory and mental dysfunction (Aggleton JP, ed), pp 471-483. New York: Wiley.

Gaffan D (1992c) The role of the hippocampus-fornix-mammillary system in episodic memory. In: Neuropsychology of memory (Squire LR, Butters N, eds), pp 336-346. New York: Guilford.

Gaffan D (1994) Dissociated effects of perirhinal cortex ablation, fornix transection and amygdalectomy: evidence for multiple memory systems in the primate temporal lobe. Exp Brain Res 99:411-422. 
Grant RH, Parsonage MJ, Barot MH (1988) Phenytoin-induced gum hypertrophy in patients with epilepsy. Curr Med Res Opin 10:652-655.

Horel JA (1978) The neuroanatomy of amnesia: a critique of the hippocampal memory hypothesis. Brain 101:403-445.

Insausti R, Amaral DG, Cowan WM (1987) The entorhinal cortex of the monkey. II. Cortical afferents. J Comp Neurol 264:356-395.

Insausti R, Salinas A, Sanz E, Insausti A, Sobreviela T, Gonzalo LM (1994) The human perirhinal cortex. Architecture in controls and in Alzheimer's disease. Soc Neurosci Abstr 20:359.

Jones-Gotman M, Zatorre RJ, Olivier A, Andermann F, Cendes F, Staunton H, McMackin D, Siegel A, Weiser H-G (1997) Learning and retention of words and designs following excision from medial or lateral temporal-lobe structures. Neuropsychologia, in press.

Leonard B, Zola-Morgan S, Squire L, Amaral DG (1995) Transient memory impairment following lesions of the monkey entorhinal cortex. J Neurosci 15:5637-5659.

Mahut H, Zola-Morgan S, Moss M (1982) Hippocampal resections impair associative learning and recognition memory in the monkey. $\mathrm{J}$ Neurosci 1:227-240.

Margerison JH, Corsellis JAN (1966) Epilepsy and temporal loss: a clinical, electroencephalographic and neuropathological study of the brain in epilepsy, with particular reference to the temporal lobes. Brain 89:499-530.

Masur H, Elger CE, Ludolph AC, Galanski M (1989) Cerebellar atrophy following acute intoxication with phenytoin. Neurology 39:432-433.

Mesulam M-M, Mulson EJ (1982) Insula of the old world monkey. I. Architectonics in the insulo-orbito-temporal component of the paralimbic brain. J Comp Neurol 212:1-22.

Meunier M, Bachevalier J, Mishkin M, Murray EA (1993) Effects on visual recognition of combined and separate ablations of the entorhinal and perirhinal cortex in rhesus monkeys. J Neurosci 13:5418-5432.

Meunier M, Hadfield W, Bachevalier J, Murray EA (1996) Effects of rhinal cortex lesions combined with hippocampectomy on visual recognition memory in rhesus monkeys. J Neurophysiol 75:1190-1205.

Milner B (1980) Complementary functional specializations of the human cerebral hemispheres. In: Nerve cells, transmitters and behavior (LeviMontalcini R, ed), pp 601-625. Vatican City: Pontificia Academia Scientiarum.

Milner B, Penfield W (1955) The effect of hippocampal lesions on recent memory. Trans Am Neurol Assoc 80:42-48.

Milner B, Corkin S, Teuber H-L (1968) Further analysis of the hippocampal amnesic syndrome: 14-year follow-up study of H.M. Neuropsychologia 6:215-234.

Milner B, Petrides M, Smith ML (1985) Frontal lobes and the temporal organization of memory. Hum Neurobiol 4:137-142.

Mishkin M (1978) Memory in monkeys severely impaired by combined but not by separate removal of amygdala and hippocampus. Nature 273:297-298.

Mishkin M, Murray EA (1994) Stimulus recognition. Curr Opin Neurobiol 4:200-206.

Murray EA (1991) Contributions of the amygdalar complex to behavior in macaque monkeys. Prog Brain Res 87:167-180.

Murray EA (1992) Medial temporal lobe structures contributing to recognition memory: the amygdaloid complex versus the rhinal cortex. In: The amygdala: neurobiological aspects of emotion, memory and mental dysfunction (Aggleton JP, ed), pp 453-470. New York: Wiley.

Murray EA, Mishkin M (1984) Severe tactual as well as visual memory deficits follow combined removal of the amygdala and hippocampus in monkeys. J Neurosci 4:2565-2580.

Murray EA, Bachevalier J, Mishkin M (1989) Effects of rhinal cortical lesions on visual recognition memory in rhesus monkeys. Soc Neurosci Abstr 15:342.

Pandya D, Yeterian EJ (1985) Architecture and connections of cortical association areas. Cereb Cortex 4:3-61.

Penfield W, Mathieson GM (1974) Memory: autopsy findings and comments on the role of hippocampus in experiential recall. Arch Neurol 31:145-154.

Penfield W, Milner B (1958) Memory deficit produced by bilateral lesions in the hippocampal zone. AMA Arch Neurol Psychiatry 79:475-497.

Phillips RR, Mishkin M (1984) Further evidence of a severe impairment in associative memory following combined amygdalo-hippocampal lesions in monkeys. Soc Neurosci Abstr 10:136.

Saunders RC, Murray EA, Mishkin M (1984) Further evidence that amygdala and hippocampus contribute equally to recognition memory. Neuropsychologia 6:785-796.

Scoville WB (1954) The limbic lobe in man. J Neurosurg 11:64-66.

Scoville WB, Milner B (1957) Loss of recent memory after bilateral hippocampal lesions. J Neurol Neurosurg Psychiatry 20:11-21.

Scoville WB, Dunsmore RH, Liberson WT, Henry CE, Pepe A (1953) Observations of medial temporal lobotomy and uncotomy in the treatment of psychotic states. A Res Nerv Ment Dis, Proc 31:347-369.

Shellock FG, Curtis JS (1991) MR imaging and biomedical implants, materials, and devices: an updated review. Radiology 180:541-550.

Squire LR (1992) Memory and the hippocampus: a synthesis from findings with rats, monkeys, and humans. Psychol Rev 99:195-231.

Suzuki WA, Amaral DG (1990) The organization of cortical inputs to the perirhinal (areas 35 and 36) and parahippocampal (areas TF and TH) cortices in the monkey. Soc Neurosci Abstr 15:53.

Suzuki WA, Amaral DG (1994a) Perirhinal and parahippocampal cortices of the macaque monkey: cortical afferents. J Comp Neurol 350:497-533.

Suzuki WA, Amaral DG (1994b) Topographic organization of the reciprocal connections between the monkey entorhinal cortex and the perirhinal and parahippocampal cortices. J Neurosci 14:1856-1857.

Suzuki WA, Zola-Morgan S, Squire LR, Amaral DG (1993) Lesions of the perirhinal and parahippocampal cortices in the monkey produce long-lasting memory impairment in the visual and tactual modalities. J Neurosci 13:2430-51.

Theodore WH, Fishbein D, Dietz M, Baldwin P (1987) Complex partial seizures: cerebellar metabolism. Epilepsia 28:319-323.

Tranel D, Brady DR, Van Hoesen GW, Damasio AR (1988) Parahippocampal projections to posterior auditory association cortex (area $\mathrm{Tpt}$ ) in old-world monkeys. Exp Brain Res 70:406-416.

Van Hoesen GW (1982) The primate parahippocampal gyrus: new insights regarding its cortical connections. Trends Neurosci 5:345-350.

Vining EP (1987) Cognitive dysfunction associated with antiepileptic drug therapy. Epilepsia 2:S18-S22.

Webster MJ, Ungerleider LG, Bachevalier J (1991) Connections of inferior temporal areas TE and TEO with medial temporal-lobe structures in infant and adult monkeys. Neuroscience 191:255-281.

Witter MP, Amaral DG (1991) Entorhinal cortex of the monkey. V. Projections to the dentate gyrus, hippocampus, and subicular complex. J Comp Neurol 307:437-459.

Yasargil MG, Wieser HG, Valavanis A, von Ammon K, Roth P (1993) Surgery and results of selective amygdala-hippocampectomy in one hundred patients with nonlesional limbic epilepsy. Neurosurg Clin $\mathrm{N}$ Am 4:243-261.

Zola-Morgan S, Squire LR (1985) Medial temporal lesions in monkeys impair memory on a variety of tasks sensitive to human amnesia. Behav Neurosci 99:22-34.

Zola-Morgan S, Squire LR, Amaral DG (1986) Human amnesia and the medial temporal region: enduring memory impairment following a bilateral lesion limited to field CA1 of the hippocampus. J Neurosci 6:2950-2967.

Zola-Morgan S, Squire LR, Amaral DG (1989a) Lesions of the amygdala that spare adjacent cortical regions do not impair memory or exacerbate the impairment following lesions of the hippocampal formation. J Neurosci 9:1922-1936.

Zola-Morgan S, Squire LR, Amaral DG (1989b) Lesions of the hippocampal formation but not lesions of the fornix or the mammillary nuclei produce long-lasting memory impairment in monkeys. J Neurosci 9:898-913.

Zola-Morgan S, Squire LR, Amaral DG, Suzuki WA (1989c) Lesions of perirhinal and parahippocampal cortex that spare the amygdala and hippocampal formation produce severe memory impairment. J Neurosci 9:4355-4370.

Zola-Morgan S, Squire LR, Mishkin M (1982) The neuroanatomy of amnesia: the amygdala-hippocampus vs. temporal stem. Science 218:1337-1339.

Zola-Morgan S, Squire LR, Clower RP, Rempel NL (1993) Damage to the perirhinal cortex exacerbates memory impairment following lesions to the hippocampal formation. J Neurosci 13:251-265.

Zola-Morgan S, Squire LR, Ramus S (1994) Severity of memory impairment in monkeys as a function of locus and extent of damage within the medial temporal lobe memory system. Hippocampus 4:483-495. 